Ärztliche Erfahrung beschränkt sich nicht auf medizinisches Fachwissen.

Sie entsteht auch aus den mehr oder minder alltäglichen, heiter,

\title{
Das neue, flauschige Teammitglied feiert Erfolge
}

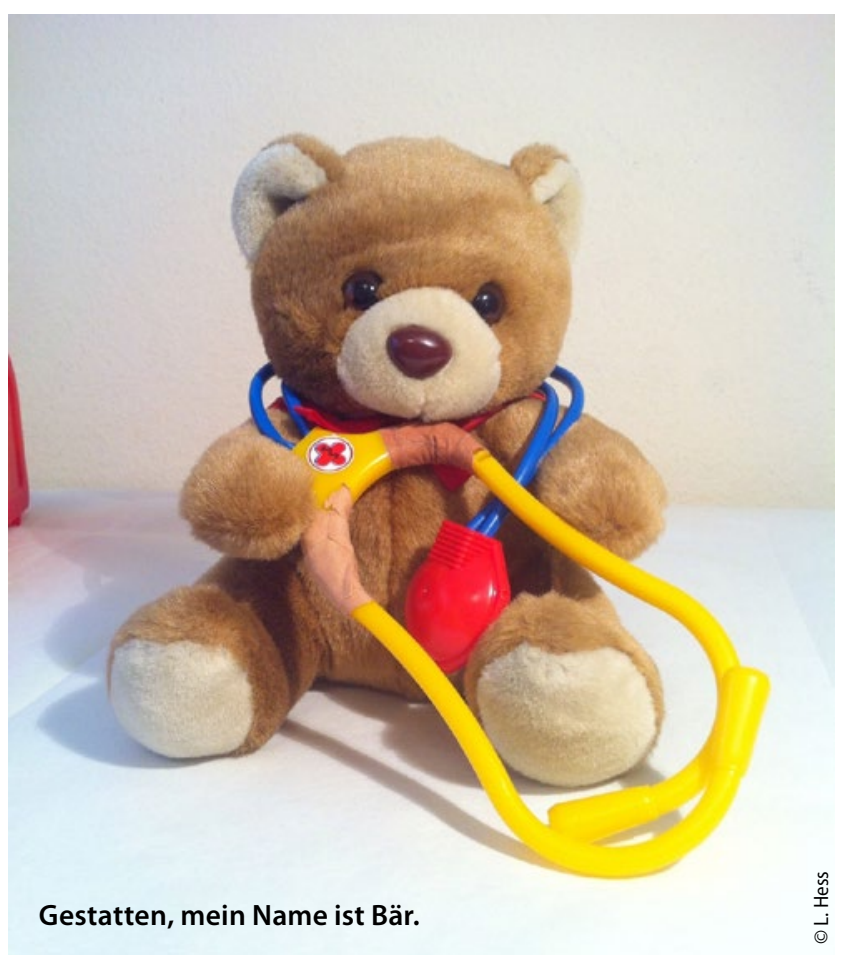

— „Den nehme ich mit in die Praxis!“, dachte ich, als mir beim Aufräumen ein kleiner Teddybär (siehe Foto) in die Hände fiel. Ich malte mir aus, wie ich das Stofftier einem Kind während einer Untersuchung in den Arm legen und es so ablenken könnte. Warum war ich darauf vorher nie gekommen?

Schon gleich am nächsten Morgen tauchte ein geeigneter kleiner Patient in unserer Praxis auf - und der Bär tat uns keinen Bärendienst, sondern brachte das weinende Kind im $\mathrm{Nu}$ zum Strahlen. „Na also!“, frohlockte ich.

Ganz beschwingt behandelte ich den nächsten Patienten. Doch wehe! Als ich danach aus meinem Sprechzimmer kam, um den Übernächsten aufzurufen, war nicht nur die Mutter mit dem Kind verschwunden, sondern obendrein auch noch meine Arzthelferin - und der Bär, der doch gerade erst so einen tollen Einstand gefeiert hatte. Kurz traten mir Schweißperlen auf die Stirn, doch nach ein paar Minuten kam meine Helferin zurück, abgehetzt zwar, aber mit dem Bären in der Hand. „Ich bin hinter dem Kind hergerannt, um ihm seinen Bären zu bringen“, berichtete sie. „Aber er gehörte ihm gar nicht!“ Das nenne ich Einsatz. Beruhigt erklärte ich, dass es sich um den neuen Praxisbären handelte - und er ab sofort ein vollwertiges Teammitglied sei.

Dr. Luise Hess, Darmstadt

\section{Kleine Ornithologie für kleine Ohren}

_Wenngleich das Gefühl der Ehrfurcht heutzutage immer seltener empfunden wird, bleiben wir Ärzte zumindest für viele unserer kleinsten Patienten wahrlich noch Halbgötter in Weiß. Es ist manchmal rührend, wie die Kinder automatisch davon ausgehen, dass unsere Worte einer tieferen Weisheit entspringen.

Ich erinnere mich an ein kleines Mädchen, das in Begleitung seiner Mut- ter in meine Sprechstunde kam und krampfhaft ein Kinderbuch in Händen hielt, das es aus der Spielkiste im Wartezimmer hervorgekramt hatte. Kaum hatte sie auf dem Stuhl Platz genommen, schlug die Kleine das Buch auf und versuchte, den dargestellten Bildern die entsprechenden Namen zuzuordnen. Unaufhörlich glitt ihr kleiner Zeigefinger über die aufgeschlagene Seite, bis er schließlich auf einem bunten Papagei verweilte. Fragend schaute sie mich dabei mit ihren kleinen Äuglein an.

„Das ist ein Papagei!“ sage ich freundlich. Daraufhin stellte sie eine typische Kinderfrage. „Und wo ist Mammagei?“, wollte sie wissen. „Weggeflogen - wahrscheinlich zum Einkaufen!“, antworte ich mit einem breiten Grinsen. Das leuchtete der Kleinen ein, und sie gab sich mit der Info zufrieden.

Dr. Udo Fuchs, Hamburg 